\title{
Sari, Femininity, and Wall Art: A Semiotic Study of GuessWho's Street Art in Bengaluru
}

\author{
Benson Rajan \\ O.P. Jindal Global University (India)
}

Graffiti has been conversing with the public for millions of years. In India, this art form is prominent in spaces like historical monuments, schools, colleges, classrooms, public bathrooms, benches, desks, and local transports. With the coming of the Covid 19 pandemic, this art from the streets has come alive in people's smartphones. This paper explores and interprets the works of GuessWho, a prominent stencil graffiti artist working in the city of Bengaluru, Karnataka, and originally belonging to Kochi, Kerala. This study seeks to understand how the discourse around graffiti can help empower women in their struggle to claim the streets. By focusing on Instagram as a medium of social resistance, the paper explores the role of graffiti and social media in challenging the patriarchal status quo. Semiotics is used to understand the ways in which the production and consumption of forms of street art and graffiti are increasingly shaping the way Bengaluru city negotiates with gender. GuessWho's graffiti symbolically targets and contests gender discrimination and particularly challenges some of the existing classist, racist, or sexist biases by subverting the use of sari, technology, and gender roles in the artwork.

Keywords: GuessWho, graffiti, Instagram, visual semiotics, Heritage, gender, Bengaluru. 

ges as well as raises conversations around gender and urban living.

Introducing the graffiti artist, GuessWho

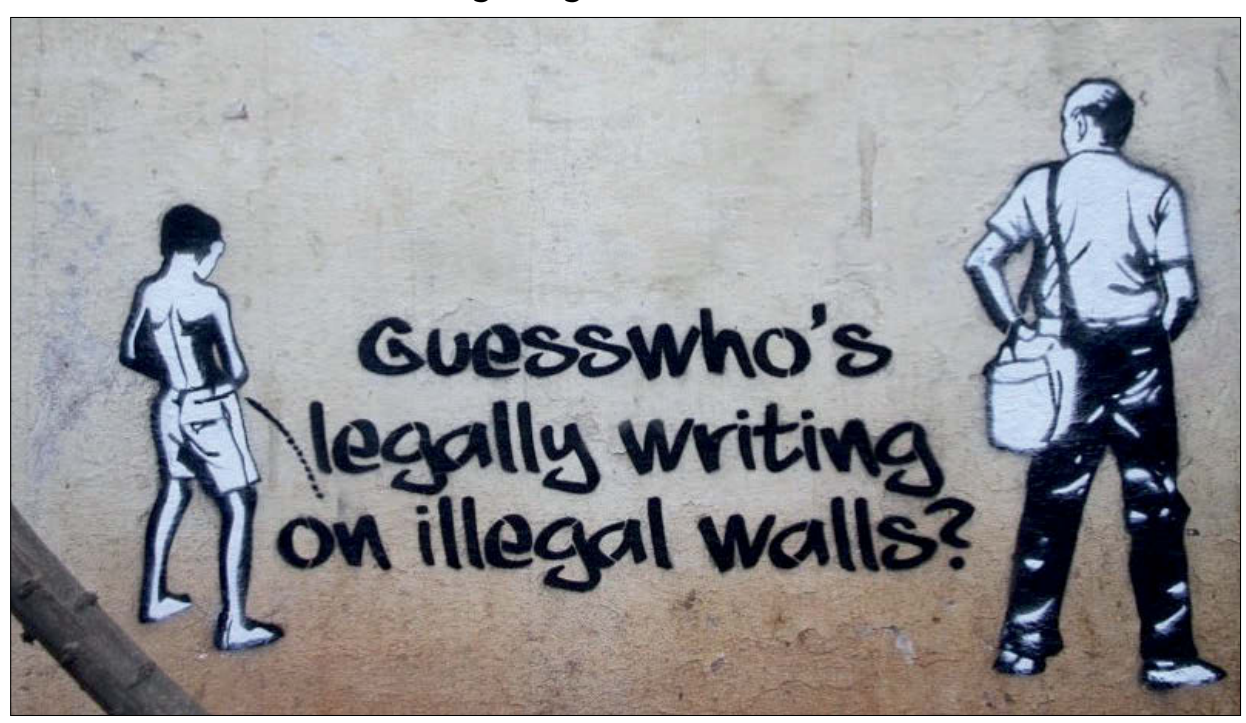

Source: @guesswhostreetart on Instagram.

GuessWho's work has been garnering an increasing attention on several photosharing sites such as Instagram, Facebook, Pinterest, and Reddit (Wendling, 2014), and GuessWho has come to be popularly known as the 'Indian Banksy' (Wendling, 2014). GuessWho's negotiations with threats of vandalism are similar to Banksy's, which has prompted both the artists to work towards maintaining their anonymity. The artists use this anonymity to effectively spread political and social messages to the public. Their artwork, in their depiction of struggle against poverty, invisibility, and a quest for dignity, are symbolic and often challenge the status-quo. Such street art invokes a dialogic encounter between the urban heritage of the city and its people.

GuessWho's graffiti acknowledges the interplay of gender and heritage in creating a holistic and gender-inclusive urban narrative for the present and future generations of Bangaloreans. This study seeks to understand how the discourse around graffiti can help empower women in their struggle to claim the streets. By focusing on Instagram as a medium of social resistance, the paper explores the role of graffiti and social media in challenging the patriarchal status quo.

\section{LITERATURE REVIEW}

Bengaluru has seen its name change from Bengaluru to Bangalore and now back to Bengaluru. Such shifts in the city's nomenclature signify the multiple layers of 
transformation it has undergone since its foundation in the 16th Century (Nair, 1998: 54). In its earliest days, Bangalore was a mercantile town (Annaswamy, 2003: 83), which by the 18th Century under Tipu Sultan's governance came to be the center for trade in textiles and armaments (Srinivas, 2004: 39-43). The year 1809 marked the establishment of the cantonment in the city, creating a bifurcation along the lines of military stations and civil residency (Nair, 1998: 13). Although the city managed to avoid the drive towards industrialization in the 1930s and 1940s, 1960 onwards there was a steady growth of industrial and institutional complexes in the city (Rao and Tewari, 1999: 229). The entry of information and technology-based sector in the 1990s to Bangalore gave rise to tech parks that redefined work, play, and leisure in terms of concentrated corridors. Ever since, the city has witnessed a hegemony of immaterial labour with wealth generation being primarily concentrated in the IT-related work field (Bhattacharya and Sanyal, 2011: 43). This has raised the overall living standards of the city. Subsequently, the Bruhat Bangalore Mahanagara Palike (BBMP) has made significant efforts towards the beautification of the city. In fact, the BBMP in 2010 commissioned artists to beautify the city by painting theme-based murals on its walls (Patrao, 2020). This is unlike the disruptive image of graffiti as understood in the western context.

Etymologically, the word graffiti originates from the Greek term "graphein" meaning to write. The word was used to describe inscriptions on ruins, prominently found at the Roman catacombs and ancient sepulchers (Whitehead, 2004: 26). Today, graffiti refers to any kind of words or drawings that is scratched or scribbled on a wall. Since graffiti is usually made without permission, it is seen as an act of vandalism. In the late 1960s and 1970s, graffiti became popular as a dominant youth activity especially among the poor, working-class population in urban New York and Philadelphia (Belton, 2001). By the early 1980s graffiti had come to be a part of the hip hop culture and it started gaining recognition as an artful expression rather than just being known for public vandalism (Belton, 2001).

In the Indian context, however, graffiti has quite a nuanced history. The cave paintings found in Ajanta, Maharashtra dating back to the second century $\mathrm{BC}$, are the oldest surviving evidence of large murals in India (Mitra, 2004: 11). There also exist various forms of folk art that have been ornamenting the walls of indigenous tribal huts and compounds for hundreds of years (Bhasin, 2018: 112). Similarly, the décor of the Indian cityscape is dominated by Bollywood posters (which even a few decades back were hand painted), signboards, slogans, and announcements of various political and other rallies. Interestingly, these forms of visual expression are also met with certain opposing forces. It is quite common to witness a culture of disregard for public walls, particularly in the urban spaces, as many of the walls are either splattered with paan ${ }^{1}$ stains (Gade, 2019) or are used as sites of public urination. Amidst the general apathy towards public walls, the enforcement of vandalism laws on those who engage in graffiti comes across

1 Betel leaf with areca nut is widely consumed throughout India. It is chewed for its diverse effects and it is usually spat out once the effects wears off. 
as impractical. Under the West Bengal Prevention of Defacement of Property Act, 1976, graffiti is an offense and an offender is punishable with imprisonment for a term that may extend to one year or with a fine, which may extend to Rs 50,000, or with both (Kapur, 2014). Against this background, it is interesting to see how various Indian cities in the recent past have provided a space and context to several graffiti artists to display their art works. For instance, artists like Daku, Yantra, Zine, Rush, and Treble have gained recognition in the domain of Indian street art and graffiti (Shukla, 2012) with their works on display on buildings, metro stations, flyovers, and several other urban sites.

\section{STREET ART AND NEIGHBORHOOD ECONOMY}

Graffiti art in India has had to adapt to its socio-communal demands (Griffin, 2019). Majority of graffiti artists are closely working with local communities in a participatory enterprise that is focused on beautification of neighborhoods and on educating the local residents. Often, a neighborhood body or a group of artists obtain permission from the residents of a certain area to paint the walls of their buildings. Some of the popular street art sites include Lodhi Art District and Shahpur Jat in New Delhi, Sassoon Dock Art Project and Marol Arts Village in Mumbai, and Wise Walls Project in Saur, Uttarakhand. Even street art festivals - such as the ones by St+art India Foundation, Delhi street art, Shillong Street art festival, and the Kolkata street art festival - have been significant in providing commissioned work to graffiti artists (Gade, 2019; Griffin, 2019). Collaborations also take place between artists and governmental bodies such as the Ministry of Urban Development, New Delhi Municipal Council, Delhi Metro Rail Corporation, Central Public Works Department, Mumbai Port Trust, BBMP, and others. However, the agenda for such commissioned street art projects is to beautify the streets and create a sense of vibrancy in the urban and semi-urban spaces; as such, they are generally un-offensive and devoid of any overt political message (Bhasin, 2018: 113). Sebastian Moody argues:

The conditions of late capitalism have made it possible for street and graffiti artists to work seamlessly with the corporate interests they have traditionally been in opposition to (2014: 25).

Graffiti, thus, has become part of the process of gentrification of upscale neighborhoods, rather than symbols of protest as witnessed in the western perspective (Whitehead, 2004: 29).

There is a strong economy-based discourse surrounding graffiti art in India. For instance, in Bengaluru, the Aravani Art Project has been actively using street art in areas such as Bellandur, Freedom Park, Dhanvantri Road, and K R Market to advocate for transgender rights (Nandhakumar, 2018). However, irrespective of the message, the primary purpose of such street art is to revamp the dull, drab, and often dirty walls of the city. According to the BBMP, the aesthetics of the art should discourage people from sticking bills, urinating, and putting up posters 
on the walls (Gade, 2019), thereby, elevating the socio-economic status of a neighborhood and promoting an upscale vibe in support of owners of high-end boutiques and designer shops. Moreover, the cost of procuring the resources and creating a graffiti is significantly higher in India in comparison to some of the western countries. In India, one can of spray paint costs around 2,000 or more. Many artists are unable to afford the exorbitant costs involved in graffiti-making unless they receive some form of sponsorship (Singh, 2018: 31). Therefore, in India, graffiti is predominantly helmed by middle-class artists. There is also a deep sense of hierarchy and privilege involved since most sites of graffiti projects happen to be marginalized neighborhoods and derelict parts of the metropolis which the artist then has to upscale with his creative work. For instance, in Dharavi ${ }^{2}$ when graffiti artists come from outside the slum to paint the walls of the slum, it generates a sense of a neo-colonialist approach of civilizing the slum. The implications are similar when artists like Daku make statements such as "metro stations and railways are signs of progress; I don't want negativity associated with my work" (as cited in Gade, 2019). In such cases, there is a categorical erasure of the resistant culture that has been associated with graffiti as a form of artistic expression. There, however, exist spaces where graffiti continues to serve as a medium of protest, to voice dissent -in Kashmir since the 1970s graffiti has been occupying the centerstage of various protests for civil liberties (Ashiq, 2015). Unfortunately, the artwork of dissent gets whitewashed and quickly removed from the public sphere. It is in this context that social media provides artists with a new space where their can survive beyond the crackdown of the authorities. Instagram, in particular, has aided in expanding the audience base of graffiti artists, and it is also shaping the practice and consumption of graffiti in general (MacDowall and Souza, 2018: 5). Indian graffiti artists are conscious of the reach Instagram has and increasingly, artists are choosing to disseminate their art through this medium.

\section{\#INSTAGRAFFITI AND BENGALURU}

Instagram, a social network platform for photo and video sharing, provides a virtual space for street art to survive and it distributes the graffiti beyond its vernacular context of creation (Burgess, 2006: 204). The affordances of Instagram provide a collation of styles, grammars, and logics of representation to an artist, where they can select the frame, the resolution, different styles of filters to exhibit their artwork (Gibbs et al., 2014: 257). Filters that provide high color contrast and saturation add to an increased visual impact of the art on Instagram. Together, the framing and the filter contribute to the visceral experience of consuming street art in the online mode. For instance, the feed appears to be in a visual flow as the images are categorically organized to create a photo album, and the filters give the images a signature 'install' look that is similar to traditional graffiti pieces.

2 Asia's largest slum situated in Mumbai, India. 
Many graffiti artists in Bengaluru expressed that the world at large learned about their artwork through Instagram. Since the platform does not mandate the use of actual names in its handle, graffiti artists can successfully connect with their audience without having to reveal their real identity. They can also share their official website details and e-mail addresses through private chat option or user bio to solicit further contact from their audience. Today, Instagram has emerged as the principal domain via which artists receive project offers and requests for collaborations from their followers (Monalisa, 2020).

Nevertheless, graffiti artists do take significant risks by publishing their work on open access networks and in geo-tagging their posts. Government authorities can potentially follow or track down an artist based on their online activity. Therefore, even on Instagram users need to carefully mediate their (in)visibility to minimize their risk of being identified or tracked by authorities.

\section{GENDER AND HERITAGE ON THE STREETS}

Bengaluru has a history as the capital of domestic violence, dowry deaths, and inhuman acid attacks on women (Roy, 2020; Lankesh, 2017). The city, according to Lankesh (2017) in the 1990s and 2000s provided women with a sense of safety in the streets. The women enjoyed certain privileges, which their counterparts in other cities didn't possess. In the 90's unwed couples could easily find rental accommodation; bar hopping or strolling on the streets late in the night didn't attract harassment for women (Lankesh, 2017). However, in recent years Bengaluru has seen a surge in atrocities against women in public spaces. The atrocities against women raise important questions about women safety in Bengaluru and how women can reclaim their streets without fear of harassment?

Shilo Shiv Suleman, artist and founder of the fearless collective, and the Aravani Art Project, a Bengaluru based women and transwomen art collective, are amongst those who have been using graffiti to voice the need for inclusion of the marginalized gender and women. They encourage women to narrate their stories and reclaim public spaces through art. Their work engages with the representation of female desire, and gender equality, and they are known to target the busiest intersections in the city, which historically have been deemed unsafe for women. Amidst such creative endeavours in the city, GuessWho's work has also found a voice. GuessWho's graffiti has challenged the heritage of genderbased divisions that play out in the streets of Bengaluru. This paper engages in a semiotic analysis of GuessWho's street art, which becomes the framework for interpretation gender relations on the streets as well as exploring the role of Instagram in informing and shaping the street art for the Netizens.

\section{METHODOLOGY}

The paper uses visual semiotics to analyze the gender-oriented street art of GuessWho. Street art like other visual representations transfers meanings 
appropriated from various cultural 'referent systems' such as nature, history, and culture, and these become the connotated meanings (Williamson, 1978: 100) of the street art. This connotative transfer requires the audience on the street to make the connection with the symbolic elements so that the significance of the various signs embedded in the art is understood (Williamson, 1978: 19). Kress and Van Leeuwen's framework of visual semiotics is applied to this study of street art as it takes into consideration the audience's interaction with the art. There are three principal frameworks of visual semiosis used to analyze street art:

1. The representational dimension explores the narrative process and conceptual ideas inherent in the visual. Here, the meaning-making process arises from the differences between signifiers in their association with each other or commonly known as paradigmatic analysis (Saussure, 1983: 121). The paradigmatic relations are contrasts and they use differentiation or substitution with other signifiers or absent signifiers of visual text. The other signifiers build the structural forms for signs to make sense or assist the signs to be organized into codes (Saussure, 1983: 122).

2. The 'meta-function' of the image's interaction with its viewers. Here, the gaze of the visual object is categorized into close, medium, and long view. This is the view of the audience to the personified objects of the graffiti and how they are framed in the visual. Kress and van Leeuwen discuss how such images make demands from the audience when the gaze of the visual object is directly looking into the audience. This connects the audience with the digital object at a formal as well as the imaginary level (Kress and Leeuwen, 1996: 122-123).

3. Kress and Leeuwen's (1996) analysis of modality is a context-dependent claim to credibility or truthfulness of an image. The truthfulness can be judged on the degree of contextualization, color, and comprehensiveness of representation (Kress and Leeuwen, 1996: 256). For this study, modality is context-dependent focusing on sensory coding. The values are distinguished along with the variables of high, medium, and low. For street art, the criteria of colors will be used to set the value of modality:

- High sensory modality: images that naturalistically are high in saturated colors.

- Medium sensory modality: images that have washed out or carry an ethereal essence.

- Low sensory modality: monochromatic images that represent traditions of fine art, leaning primarily towards abstraction or classified as fantasy.

For the study, the Instagram page of GuessWho (guesswhograffiti) was used to collect sample graffiti for analysis. With around 10,500 followers on Instagram, GuessWho is renowned for street art that demands a critical engagement with gender issues. Permission for representing graffiti for academic research was obtained from GuessWho via Instagram.

Purposive sampling was employed to identify and shortlist graffiti from the 218 posts as of the 4 th of February 2021. The following hashtags were utilized 
118 to identify graffiti from Bengaluru that challenged gender representation on the street: \#streetartbangalore, \#thefutureisfemale, \#genderstereotypes, in \#graffitibangalore \#guesswhostreetart. Five graffiti were selected from Instagram - $\quad$ that fit the objective of the study for semiotic analysis:

- To understand the discourse of the graffiti to claim the streets for women.

- The role of Instagram in its influence on street art and its conversations.

\section{ANALYSIS}

Kress and Van Leeuwen's framework of visual semiotic is applied to the five different artworks by GuessWho to understand the larger implications of drawing art out of galleries and onto the streets of Bengaluru.

Figure 1. Breaking gender stereotype through art

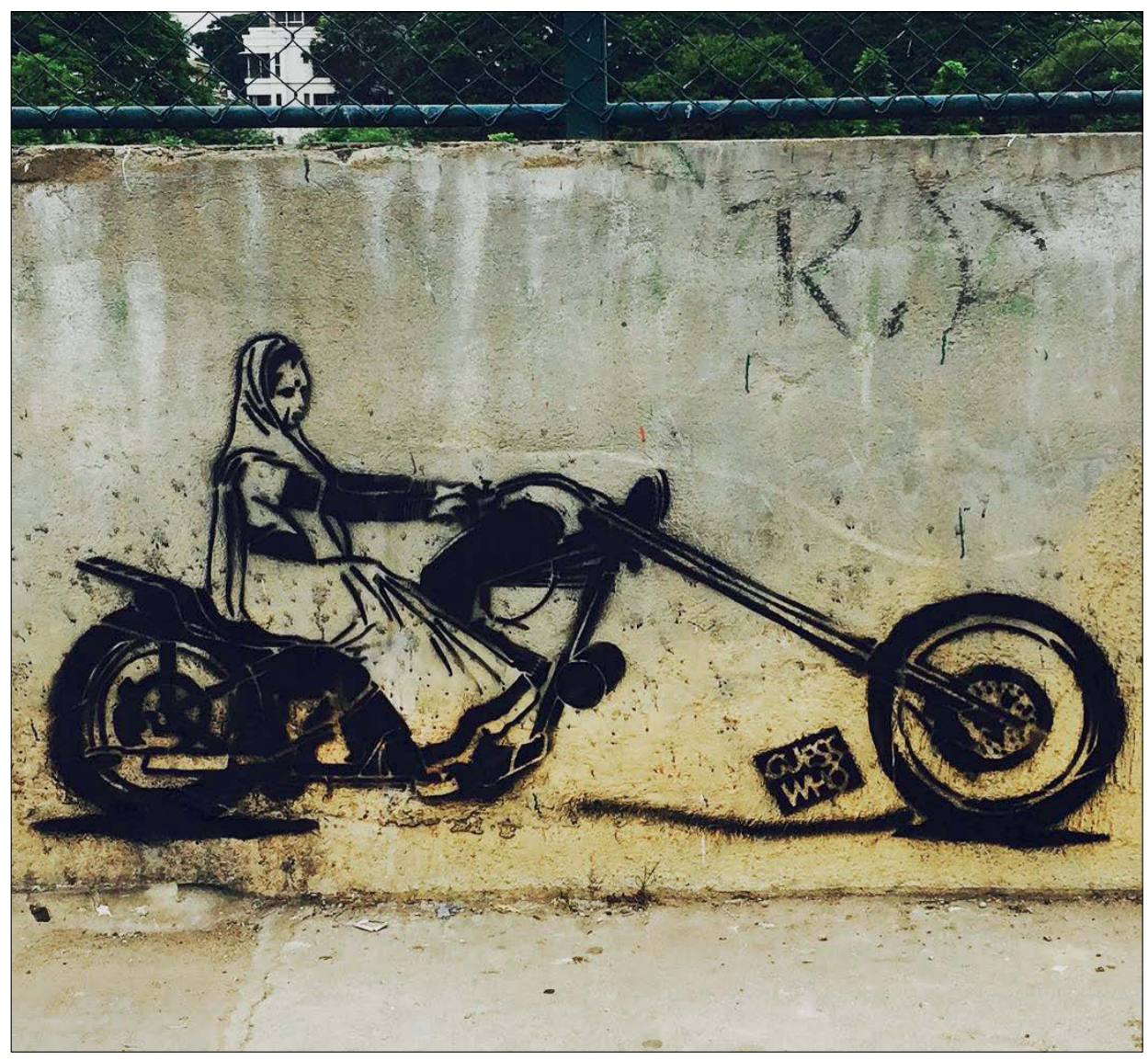


1. The narrative process highlights two dominant signifiers: a woman wearing a sari ${ }^{3}$ and a cruiser bike (similar to an American chopper). ${ }^{4}$ The draping of the sari positions the woman within a rural or semi-urban background. The sari is draped in Nivi style, with the pallu ${ }^{5}$ drawn over the head to depict a 'sanskari', 6 married woman. She is also seen wearing rubber chappals - a common variety of slippers worn indoors in most middleclass Indian households while also worn outdoors by people belonging to a lower economic background- while riding the bike. Women of her socioeconomic status sporting the sari are usually pillion riders who sit sideways with their legs dangling on one side of the bike.

2. In India, the sari has come to symbolize culture, tradition, values, and heritage. The sari is not only deemed in many regional cultures as the attire of a married woman, it is also categorized as formal wear in the Indian professional setting. The sari continues to be involved in the debate between tradition and modernity. With globalization affecting the sense of fashion and personal style especially in metropolitan spaces like Bengaluru, young, professional women in these urban center's can be seen moving beyond the sari and experimenting with 'less conventional' items of clothing. However, the graffiti in representing a woman donning the sari while riding a bike somewhere frees the sari of its conventional image.

The stance of the women in this graffiti is particularly masculine. The denoted curser bike carries contrary connotations of a powerful masculine machine where 'style trumps practicality'. It also prompts the viewer to conjure up images of old school backyard builders and do it yourself (DIY) activities that have a general disregard for restrictive rules and regulations. Therefore, the image of the bike encourages its riders to take up an adrenaline-filled lifestyle of adventure and thrill. When we transfer these connotative meanings to the women in graffiti, it shows the journey away from restrictive traditions that have bound the older generation of women in the cities. The woman in the graffiti is seen moving beyond the domestic space and taking control of the external world. She no longer rides pillion. Instead, she breaks the stereotype of a traditional woman by taking control of her sexuality as well as her independence in the streets of Bengaluru.

The graffiti brings forth several binary oppositions such as tradition versus (vs) modern; customary vs progressive; masculine vs feminine; human vs

3 A women's garment from the Indian subcontinent that consists of an unstitched drape that is typically wrapped around the waist, with one end draped over the shoulder. It is a functional garment that can be worn for everyday use as well as for formal occasions.

4 Custom built motorcycle with cruiser styling that started in the late 1950's in California.

5 The loose end of a saree that is put over the shoulder.

6 A term used to describe whether or not a women exhibits the ideal qualities of a 'cultured Indian woman'. 
machine; indoor vs outdoor; inclusion vs exclusion; rich vs poor; public vs private; strong vs weak; majority vs minority; strange vs familiar.

3. The gaze of the woman, as seen in the graffiti, is directed towards the road, away from its audience. This allows the audience to participate as 'invisible onlookers' whose validation is neither requested nor sought after by the woman (Kress and Leeuwen, 1996: 124). The interaction is implying a statusquo and the image is also at a social distance in terms of proxemics which distances the onlookers from participating.

4. The image has low sensory modality as it is monochrome. Thus, it is closer to fantasy than naturalistic representation.

Figure 2. Redefining masculinity

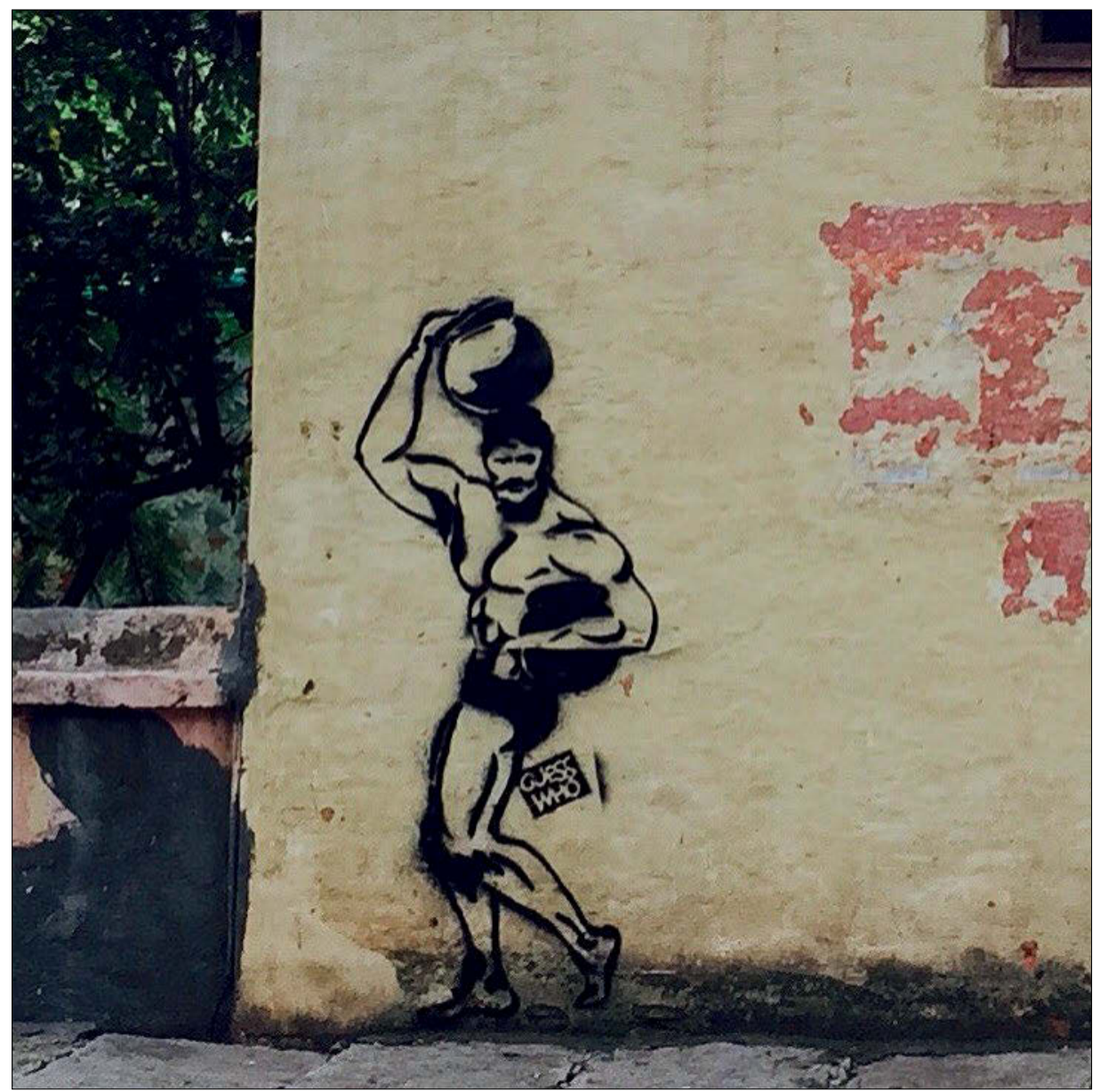

Source: @guesswhostreetart on Instagram. 
1. Figure 2 shows a bodybuilder carrying pots of water. There are definite gender underpinnings to this work. In urban slums and rural villages, the task of collecting water has traditionally been assigned to women (Caruso, 2017), and globally, more women are engaged in providing water for their households as opposed to men. Daily chores such as cooking, bathing, cleaning are managed based on the ability to procure enough water, a task that involves spending hours (often several times a day) walking long distances in search of water, waiting in line to fill up the pots, and then carrying back the heavy loads back to the homes. The responsibilities that women take up in their domesticities, which go completely unpaid, often lead to loss of employment opportunities, education, leisure, and even physical rest for them.

2. The connotation of a bodybuilder carrying pots of water emphasizes the notion of 'fake strength'. In the patriarchal social set-up, the strength of a man is measured through a display of physical prowess. This also involves a performative display of strength where men accentuate their bodies through muscle-building exercises in 'akharas'7 and gyms — as shown in the graffiti where the bodybuilder can be seen showing off his musculature- to convey strength and toughness. However, the true functional strength lies with the women who haul around 50kg worth of water daily for each member of the household (World Health Organization). Women and their invisible domestic tasks are physically demanding, and the graffiti in positioning a bodybuilder in the traditional role of a woman carrying water plays with the idea of role reversal. The graffiti, thus, opens up a discourse that questions the gendered nature of domestic, unpaid labour and challenges the inequalities inherent in such a social structure.

Once again, the graffiti highlights the binary oppositions between masculine vs feminine; men vs women; strong vs weak; work vs leisure; appearance vs reality; competence vs performance.

3. The bodybuilder's gaze in the graffiti is directed at the audience demanding an engagement. There is a cold disdain in the gaze that almost asks the audience to admire the performance of masculinity. The gaze is inviting the audience to come closer and form a bond with the graffiti by taking up the challenges of domestic chores. The proxemics is at a close social distance that allows a low form of intimacy with the image similar to everyday face to face interaction (Hall, 1963: 1013).

4. The image is similar to Figure 1 as it is also monochromatic and has low sensory modality. Therefore, it is closer to fantasy than to naturalistic representation. 


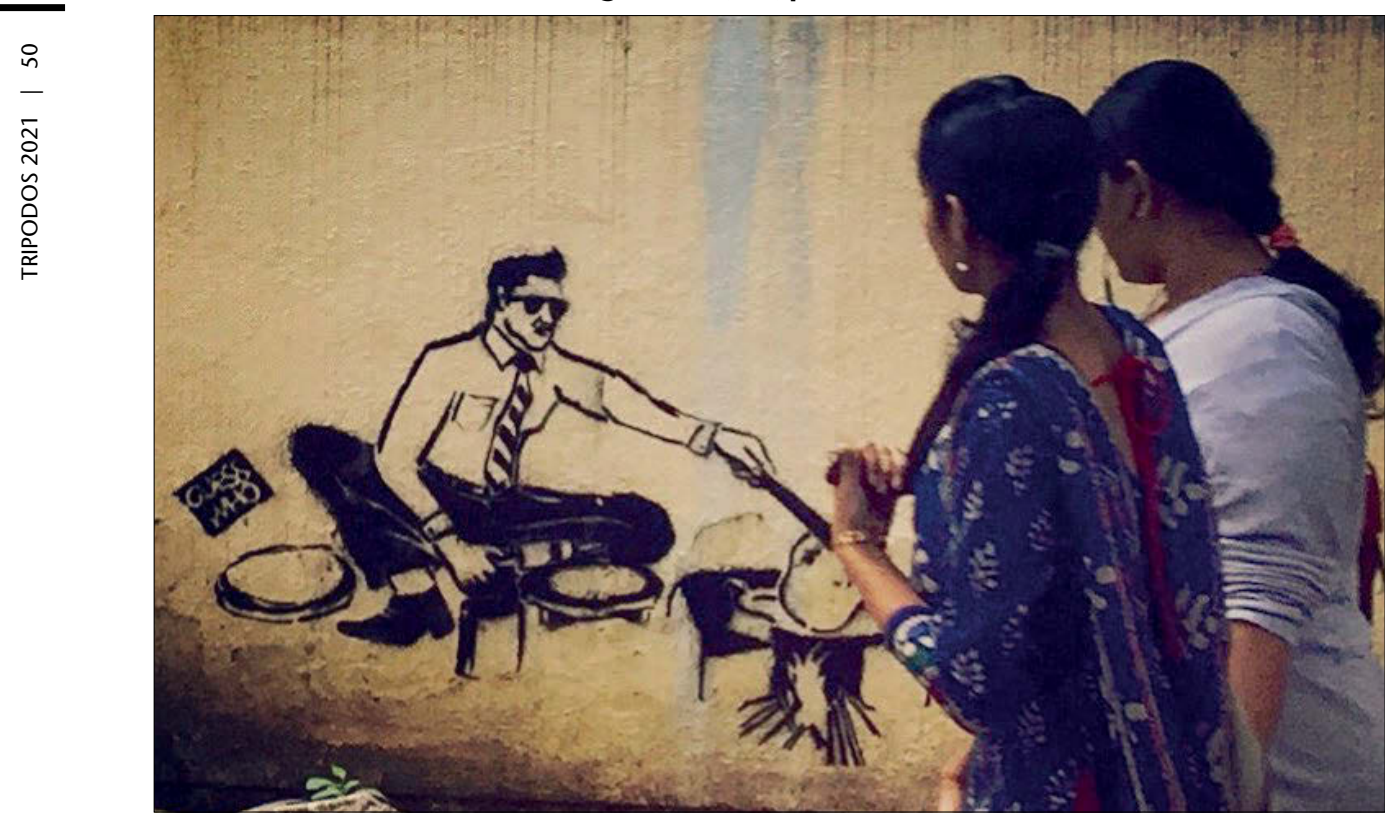

Source: @guesswhostreetart on Instagram.

1. The graffiti shows a working man cooking lunch/dinner. The traditional, rural style of cooking is emphasized as the man can be seen preparing rotis ${ }^{8}$ on an earthen 'chulha' ${ }^{\prime}$ as opposed to a gas stove. The image contains all the necessary resources involved in roti-making — chakla and belan (the board and the rolling pin used to flatten the dough and shape the roti); tawa (griddle); chimta (tongs used to flip the roti), plate (to store the roti once they are baked), and dabba (a lunch box to pack food for work). The man is seen sitting cross-legged, a posture commonly used by rural women when making rotis.

The audience's attention is immediately drawn to the formal clothes worn by the man. By showcasing a stereotypical working man doing household chores such as cooking, GuessWho is raising questions about the unpaid nature of household work. Although the outfit of the man in the graffiti suggests that he hails from the upper-class, he is positioned in a lower-class household as is evident from the earthen stove. The obvious contrast blurs the socio-economic differences by collapsing the worlds of the social classes through one of the banal yet necessary activities, that of

8 A round flatbread native to the Indian subcontinent.

9 Earthen stove. 
cooking. GuessWho is also giving visibility to the kitchen, a space where women spend numerous hours engaged in cooking, an activity that like the task of collecting water goes paid.

The conceptual idea and structure of this graffiti challenge the rigidly gendered spaces within a household. It seeks to break the patriarchal norms surrounding the division of labour and highlight the importance of sharing household tasks and consider it equivalent to paid labour. The graffiti underlines the binaries of public and private, masculine and feminine, man and woman, and paid work and unpaid work.

2. The man looks away from the audience and his gaze is fixed on the task of cooking. Thus, similar to Figure 1 it allows the audience to participate as an 'invisible onlooker' (Kress and Leeuwen, 1996: 124).

3. Like Figures 1 and 2, this graffiti too is in monochrome and has low sensory modality as it is monochrome. Therefore, it is closer to fantasy than to a naturalistic representation.

Figure 4. Gendered aspirations

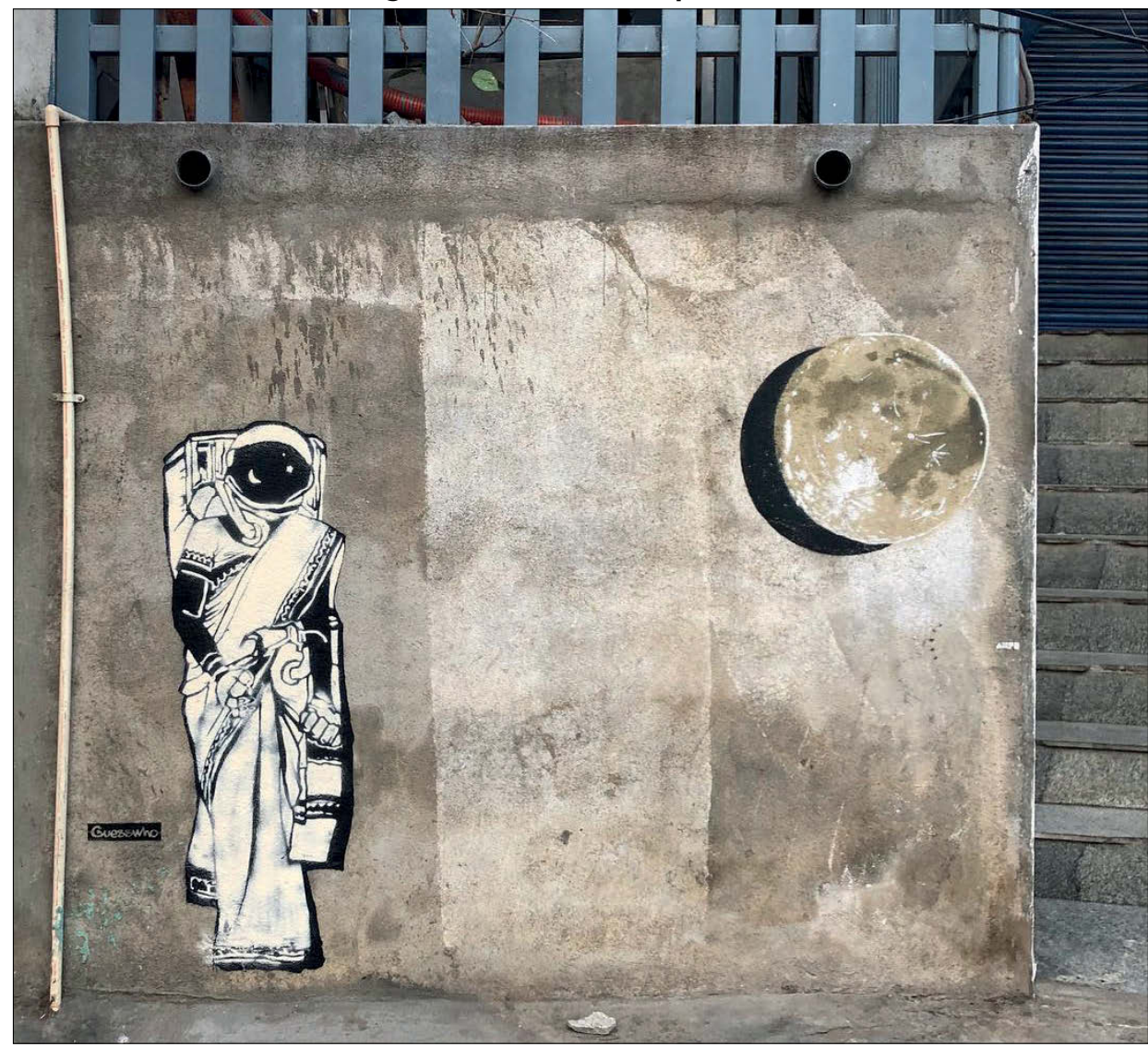


1. The image above denotes a woman in a traditional sari attached via a harness to a primary life support subsystem. The woman is also seen wearing the Valsalva device/helmet that hides her face. The face shield of the helmet reflects the moon and the stars. Towards the top right corner of the frame, one can also see a much larger depiction of the crescent-shaped moon.

The sari in this graffiti has similar connotations to the ones already discussed in Figure 1. However, the drape in this image is more formal. Here, sari becomes a tool for power dressing and consequently, the graffiti becomes a representation of empowered women. Metaphorically, then, the graffiti upholds the dreams and aspirations of every woman to reach for the stars. Besides, India is yet to send a woman to space. The graffiti, thus, points to the lack of female astronauts in India.

In a different vein, the graffiti also challenges the practice of defining a woman in relation to the man. In several parts of India, women celebrate Karwa Chauth, a festival where women fast during the day and pray for the longevity of their husbands. The festivity involves looking at the moon through a sieve in the evening, post which the husband offers a glass of water to the wife, thus, breaking her fast. The romanticized depiction of this festival in Indian popular culture has popularized a certain category woman who are identified by their devotion to their husbands and their belief in traditional value-systems. By portraying a saree-clad woman in a spacesuit, the graffiti suggests that women do not need to be identified in relation to a man. Instead, they can be defined by their professional choices. The graffiti is also a larger commentary on the existing gender divide and lack of representation at workplace and the continued strive for gender equality.

This graffiti emphasizes the opposition between tradition and modernity, tradition and modernity, belief and science, sacred and profane.

2. The woman's gaze is not visible as the helmet prevents the audience from deciphering in which direction the woman is looking at. However, the posture of the body suggests that the woman is looking directly at the audience and demanding an engagement. The gaze is inviting the audience to come closer and see the reflections in the helmet. The movement encourages a bond with the graffiti. The proxemics is at a far social distance that illustrates the gender divide which needs to be sealed by the audience.

3. Similar to Figures 1, 2, and 3 this one also has low sensory modality as it is monochromatic. However, the moon is depicted in highly saturated colors, which gives it a naturalistic outlook as opposed to the rest of the image. 
Figure 5. She-Can

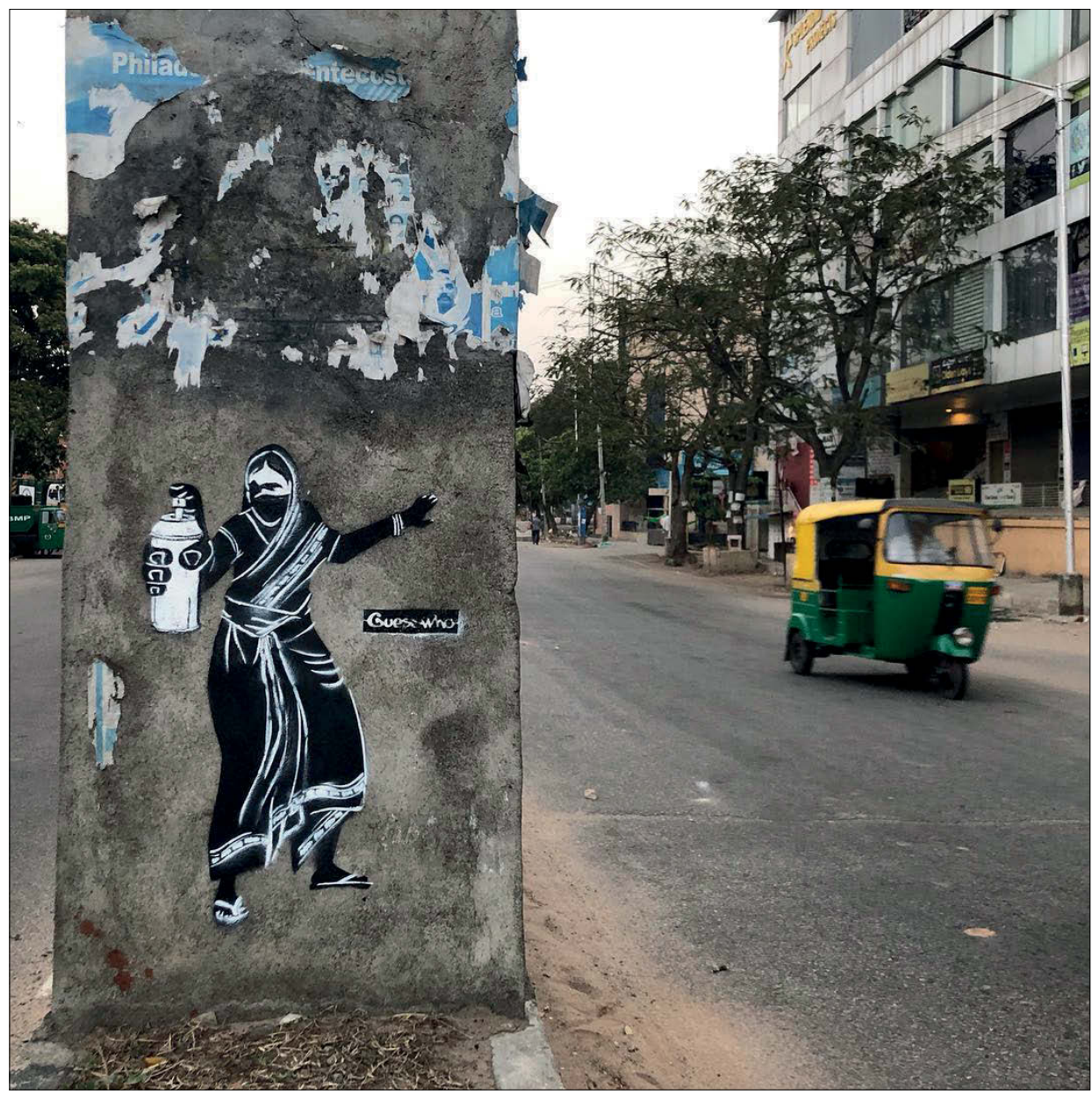

Source: @guesswhostreetart on Instagram.

1. The graffiti is made on a metro rail pillar. It depicts a woman in a sari that is draped in the Nivi style. However, this style of draping the sari differs from Figure 1 and 4 . Here, the pallu (the loose end of the sari) is tucked around the waist to allow for a greater freedom of movement. This style of draping is common among women who engage in more physically challenging labour such as sweeping and mopping, working in the agricultural fields or construction sites, etc. In the urban spaces, it is the housemaids that drape the sari in the style illustrated above. The draping around the waist in particular is symbolic and is popularly used to signify that the woman is preparing herself for exertion. Moreover, the popular culture has associated this style with the idea of 'preparation in anticipation of hard physical labour' as well as aggression. This style of a drape also makes a statement on 
the socio-economic background of the wearer as it is not a style one would see women in the corporate, or in the academia or in any white-collar work environment sport. It is primarily seen amongst women from the lowerincome households who engage in manual labour, which demands freedom of movement. That the woman in the graffiti is also seen in a pair of rubber slippers further emphasizes the idea that she belongs to the lower strata of society (as discussed under Figure 1). Her use of the mask could suggest that she is safeguarding herself from the hazardous surrounding.

The spray can she is holding could signify two things. First, it could refer to cans of pepper spray that women carry to protect themselves against harassment or abuse. This is specifically applicable to female domestic helps. Women and girls employed in private households are often at risk of physical, and sexual abuse by the employers. These risks are heightened given their isolation, the imbalance of power between the employer and the domestic worker. The image of the can, thus, becomes symbolic of fighting back and standing up for oneself. Second, it could be a color spray can used by graffiti artists. The graffiti then becomes a depiction of the process of graffiti-making. It could also imply that a person like the woman in the image, irrespective of her gender and could be a street artist.

2. This graffiti brings forth the binary oppositions between public and private, customary and progressive, masculine and feminine; man vs woman.

In this graffiti, the woman is looking away from the audience. Her gaze is fixed on the act of spraying. Thus, similar to Figure 1 and 3, it allows the audience to participate as an invisible onlooker. The use of the mask, in this regard, maintains the anonymity that most graffiti artists seek. The mask, thus, engages with concepts of freedom and liberation.

3. The image is similar to Figures 1, 2, 3, and 4. They all generally have low sensory modality as they are painted in monochrome. Once again, the representation is closer to fantasy than to naturalistic representation.

\section{DISCUSSION}

GuessWho's work is a direct challenge to patriarchy. GuessWho's street art is an invitation to women to stand up for their rights and against the meaningless restrictions and impositions of the patriarchal social order. India is one of the most gender unequal countries in the world where women face systemic discrimination that significantly increases the risk of violence they face in private as well as public spaces. GuessWho's art contests such gendered inequity pervading the public and private realms. The graffiti discussed in the paper underscore the role of women in making the male dominated economy tick in urban centers. The focus on domestic tasks emphasizes the need to bring gender equality in the domestic front, and subsequently in the professional realms.

Even in the streets, GuessWho's graffiti attempts to instill messages of equality where traditions signified through the use of Sari, which is coupled with 
masculine technologies such as motorbiking, astronomical enterprise, and even working as a street graffiti artist. These become a sign of defying the domination and segregation of living in a patriarchal society where women's lives and work are celebrated in the enclosed spaces of a house and the street belongs to the men. GusseWho is rewriting the script for taking back the streets through graffiti. The focus is to challenge the patriarchal culture via the counterculture of graffiti in the streets. Using the highly symbolic graffiti the new script for the streets of Bengaluru is being painted, that highlights the equal distribution of work, converting unpaid labour to paid labour, visibility to feminist movements from the lower strata of society, and primarily to take back control over one's body and its expressions.

Central to all the artworks discussed above is the motif of gender. Each of the graffiti's proxemic was at a social distance, away from the audience. However, the low modality markers of the graffiti highlight the realm of fantasy and contribute primarily towards gentrification and aestheticization of Bengaluru's cityscape.

BBMP's rationale behind encouraging graffiti at various locations in Bengaluru is to make art accessible for everyone and in effect, transforming common, everyday sites into new meaning-making spaces of deliberation. When displayed on the walls and streets of the city, the work reaches a broader audience that even includes those who won't go (or are unable to afford a visit) to art galleries and exhibitions. The reach significantly expands when the graffitis are also shared by artists as well as the audience on social media platforms like Instagram. The role of graffiti tags on Instagram functions as 'searchable signatures' enabling a wider circulation and a more prominent online presence. In fact, Instagram has become integral to the production and distribution of GuessWho's work.

GuessWho regularly uses generic nomenclature when tagging the artworks. For instance, \#peace \#freedom \#humanrights \#noviolence \#nice \#love \#stencilart \#stencils \#streetartindia \#indianstreetart \#nohatred \#noviolence \#speakup \#dissent \#SheCan \#YouCan. These terms, variations on graffiti and urban art practices, have an important indexical function as they reveal the socio-political underpinning of the artwork. However, \#guesswho and \#guesswhograffiti function in a more complex way as they are used in both online and offline contexts. The tags \#guesswho \#guesswhograffiti \#guesswhostreetart \#guesswhograffiti have become a different kind of traveling tag as it circulates in the hashtag economy increasing the visibility of the work. This also increases the artist's chances of landing lucrative commissioned work.

Nevertheless, such social media driven street art has come under criticism for giving precedence to Instagram posts rather than the physical spaces where the art is being formed. Here, the notion of vandalism resurfaces as local communities fear that such artworks can disrupt the aesthetics of the communal space since they are done keeping the Instagram audience in mind rather than the local community that has permitted to paint on its walls.

Although, it cannot be denied that the longevity of artworks on the digital platform is an added motivation to work along virtual and physical lines to influence the audience. 


\section{$128 \quad$ CONCLUSION}

In Bengaluru, GuessWho's street art is fighting for gender equality along with other streets art groups such as the Aravani Art Project and the Fearless Collective. Their commissioned artwork on the streets is raising an awareness on the need for gender equality. The meta-function of street art is to create a series of artwork focused on a more gender inclusive public sphere. GuessWho's has been producing iconic images on the streets that visually define gender equality. Marwan Kraidy argues:

The importance of graffiti is its ability to carry messages that, because of their radicalism or marginality, would never appear in mainstream media, especially in a system divided into sectarian media enclaves (2013: 5).

Instagram has taken GuessWho's campaigns beyond the streets of Bengaluru, starting a conversation around gender equality across online and offline platforms. It has also altered street art by bringing anonymous artists into the 'hashtag economy'. Instagram has also changed street art by altering its shape and size to fit its square format. But, even on Instagram, art must speak for itself. Therefore, the meaning-making process of the audience is addressed using semiotics.

The cultural signification of GuessWho's work is connected to the idea of curbing women's freedom of movement. Street art, then, becomes a symbolic process of reclaiming the right to the space of the street itself. Street art is also not predictable. It fades with time, but its digital footprints can live forever.

\section{FUNDING}

The author received no financial support for the research, authorship, and/or publication of this article.

Benson Rajan (brajan@jgu.edu.in) is an Associate Professor at Jindal School of Journalism and Communication, India. He specialises in visual culture and media semiotics. His research on social media, gender studies, and human computer interaction studies has been published in various journals such as Punctum: International Journal of Semiotics, Hypertext.Net, Funes: Journal of Narratives and Social Sciences, MAI: Feminism and Visual Culture, Journal of Creative Communications. His work "Curating an
Affective Push: Indian Women's Facebook Profile Pictures and Their Affective Turns" was published in Deleuzian and Guattarian Approaches to Contemporary Communication Cultures in India (2020) by Springer Nature. "Popular Culture and the (mis)Representation of Asperger's: A Study on the Sitcoms Community and The Big Bang Theory" is his latest book chapter, that was published in Normalizing Mental Illness and Neurodiversity in Entertainment Media: Quieting the Madness (2021) by Routledge. 


\section{References}

Annaswamy, T. V. (2003). Urban History of Bangalore from the Pre-Historic Period to the End of the 18th Century, Bangalore. New Delhi: Vengadam Publications.

Ashiq, Peerzada (2015, October 1). "Separatists Smear Walls, Each Other in Srinagar". The Hindu. Available at: <https://www. thehindu.com/news/national/separatistssmear-walls-each-other-in-srinagar/article 7708082.ece $>$. Accessed 25 January 2021.

Belton, Val-Jean (2001). "Racism, Gender, Ethnicity, and Aesthetics in the Art of Graffiti". Yale-New Haven Teachers Institute, 2001. Available at: <https://teachersinstitute.yale. edu/curriculum/units/2001/4/01.04.01/2>. Accessed 25 January 2021.

Bhasin, Aparajita (2018). "The Evolution of Street art and Graffiti in India". Street Art \& Urban Creativity Scientific Journal, 4(2), pp. 112-117.

Bhattacharya, Rajesh and Sanyal, Kalyan (2011). "Bypassing the Squalor: New Towns, Immaterial Labour and Exclusion in Post-colonial Urbanisation". Economic \& Political Week$l y, 46(31)$, pp. 41-48.

Burgess, Jean (2006). "Hearing Ordinary Voices: Cultural Studies, Vernacular Creativity and Digital Storytelling". Continuum: Journal of Media \& Cultural Studies, 20(2), pp. 201-214.

Caruso, Bethany (2017, July 24). "Women Still Carry Most of the World's Water". Quartz, 24th July 2017. Available at: <https:// qz.com/1033799/women-still-carry-most-ofthe-worlds-water/>. Accessed 31 January 2021.

Deeman, H. Robert (2020). "Throwback to the Future: Journey from a Garden City to the Epicenter of Digitalization". BW Smartcities. Available at: <http://bwsmartcities.business world.in/article/Throwback-to-the-FutureJourney-from-a-Garden-City-to-the-Epicenterof-Digitalization/28-12-2020-358825/>. Accessed 20 January 2021.

Gade, Satwik (2019, June 8). "Why Indian Street Art Is Not Necessarily Anti-establish- ment". The Hindu. Available at: <https://www. thehindu.com/entertainment/art/art-for-artssake-why-indian-street-art-is-not-necessarilyanti-establishment/article27671963.ece>. Accessed 22 January 2021.

Gibbs, Martin; Messe, James; Arnold, Micheal; Nansen, Bjorn, and Carter, Marcus (2014). "\#Funeral and Instagram: Death, Social Media, and Platform Vernacular". Information, Communication \& Society, 18(3), pp. 1-14.

Griffin, Peter (2019, March 26). "From Gallery to Street". The Hindu. Available at: <https://www.thehindu.com/entertainment/ theatre/from-gallery-to-street/article 26645347.ece>. Accessed 24 January 2021.

Hall, T. Edward (1963). "A System for the Notation of Proxemic Behavior". American Anthropologist, 65(1), pp. 1003-1026.

Kapur, Aarti (2014, August 15). "Violation of Defacement Act HC Puts PU On Notice". Chandigarh Tribune. Available at: <https:// www.tribuneindia.com/2014/20140815/cth1. htm>. Accessed 24 January 2021.

Kraidy, Marwan (2013) "A Heterotopology of Graffiti: A Preliminary Exploration". Orient Institute Studies 2. Available at: <https:// prae.perspectivia.net/publikationen/orientinstitut-studies/2-2013/kraidy_graffiti $>$. Accessed 28 January 2021.

Kress, Gunther and Leeuwen, Theo van (1996). Reading Images: The Grammar of Visual Design. London: Routledge.

Lankesh, Gauri (2017, January 5). "How Did Bengaluru Become Unsafe for Women - and What Can We Do to Reclaim Our Streets?" Scroll.in. Available at: <https:// scroll.in/article/825910/how-did-bengalurubecome-unsafe-for-women-and-what-can-wedo-to-reclaim-our-streets>. Accessed 31 January 2021.

MacDowall, Lachlan John and Souza, Poppy de (2018). “'I'd Double Tap That!!': Street Art, Graffiti, and Instagram Research". 
Media, Culture \& Society, 40(1), pp. 3-22. $<$ DOI:10.1177/0163443717703793>.

Mitra, Debala (2004). Ajanta. Archaeological Survey of India.

Monalisa, Monika (2020, May 24). "Bengaluru-based 3D Artist Comes with COVID-19 Safety Journals on Street Walls". The New Indian Express. Available at: <https://www.newindianexpress.com/good-news/2020/may/24/ bengaluru-based-3d-artist-comes-with-covid19-safety-journals-on-street-walls-2147476. html>. Accessed 25 January 2021.

Moody, Sebastian (2014). "The Hand that Feeds: Graffiti and Authenticity in Contemporary Brand Culture". Artlink, 34(1), pp. 23-25.

Nair, Janaki (1998). Miners and Millhands: Work, Culture and Politics in Princely Mysore. New Delhi: Sage Publications.

Nandhakumar, Sindhuri (2018, May 25). "The Wandering Artist". The Hindu. Available at: <https://www.thehindu.com/ entertainment/art/the-wandering-artist/ article23990824.ece>. Accessed 25 January 2021.

Patrao, Michael (2020, March 27). "Painting a Story on Every Wall". Deccan Herald. Available at: <https://www.deccanherald. com/metrolife/metrolife-cityscape/painting-astory-on-every-wall-818309.html>. Accessed 21 January 2021.

Rao, Prakasa and Tewari, Vinod (1999). "The Ecological Structure of Bangalore City". In: R Ram Mohan Rao and S Simhadri (eds.). Indian Cities: Towards the Next Millennium. Jaipur; New Delhi: Rawat, pp. 221-243.

Roy, Eisha (2020, December 16). "Domestic Violence Cases Double in Karnataka”. The Indi- an Express. Available at: <https://indianexpress. com/article/india/domestic-violence-casesdouble-in-karnataka-7105065/>. Accessed 30 January 2021.

Saussure, Ferdinand de ([1916] 1983). Course in General Linguistics. Translated by Roy Harris. London: Duckworth.

Shukla, Shreya (2012, May 27). "Street Smart". The Telegraph. Available at: <https:// www.telegraphindia.com/culture/streetsmart/cid/419022>. Accessed 25 January 2021.

Singh, Neha (2018). "Graffiti: A New Emerging Art Form in Indian Streets". International Journal of Humanities and Social Science Research, 4(4), pp. 30-34.

Srinivas, Smriti (2004) Landscapes of Urban Memory: The Sacred and the Civic in India's High Tech City. New York: Orient Longman.

Vasavi, A. R. (2017). "Societies in Motion". India International Centre Quarterly, 44(1), pp. 128-134.

Water Services for Health. World Health Organization: Climate Change and Human Health. Available at: <https://www.who.int/ globalchange/ecosystems/water/en/>. Accessed 29 January 2021.

Wendling Mike (2014). "India's 'Banksy' Behind Provocative Graffiti". BBC New. Available at: <https://www.bbc.com/news/blogstrending-30447979>. Accessed 20 January 2021.

Whitehead, Jessie L. (2004). "Graffiti: The Use of the Familiar". Art Education, 57(6), pp. 25-32. JSTOR. Available at: <www.jstor.org/ stable/27696041>. Accessed 24 January 2021.

Williamson, Judith (1978). Decoding Advertisements: Ideology and Meaning in Advertising. London: Marion Boyars. 